\title{
ESTIMASI EMISI GAS RUMAH KACA PADA SEKTOR BANK SAMPAH MENGGUNAKAN PENDEKATAN WASTE REDUCTION MODEL (WARM) DI KELURAHAN SEKUMPUL MARTAPURA
}

ESTIMATION OF GREENHOUSE GAS EMISSIONS IN THE WASTE BANK SECTOR USING THE WASTE REDUCTION MODEL (WARM) APPROACH IN THE VILAGE SEKUMPUL MARTAPURA

\author{
Esti Rina ${ }^{1)}$, Rd.Indah Nirta ${ }^{2}$, Rony Riduan ${ }^{3}$ \\ ${ }^{1}$ Program Studi Teknik Lingkungan, Fakultas Teknik, Universitas Lambung Mangkurat, Jl. A. Yani km \\ 35,5 Banjarbaru
}

${ }^{2}$ Dosen Pembimbing dan Staf Pengajar Program Studi Teknik Lingkungan, Fakultas Teknik, Universitas Lambung Mangkurat, Jl. A. Yani km 35.5 Banjarbaru

Email: estirinaaa@gmail.com

\begin{abstract}
ABSTRAK
Beberapa permasalahan yang dapat timbul dari meningkatnya pertumbuhan penduduk dan pertumbuhan ekonomi ialah meningkatnya jumlah sampah di Kabupaten Banjar, sebagian besar sampah dapat menyumbang GRK dalam bentuk gas metana $\left(\mathrm{CH}_{4}\right)$. Sampah yang tanpa sengaja tertimbun dalam jangka waktu tertentu bisa mengalami atau terdekomposisi serta dapat menghasilkan gas-gas yang pada akhirnya akan tersebar di udara. Oleh karena itu, perlu dilakukan pengelolaan sampah yang tepat dan ramah lingkungan agar tidak mencemari dan merusak lingkungan. Menggunankan metode WARM (Waste Reduction Model) ialah aplikasi yang berfungsi untuk menghitung emisi GRK dari sektor persampahan dengan memasukan data yang telah diperoleh ke dalam aplikasi. Hasil analisis dari penelitian yang telah dilakukan adalah keberadaan bank sampah mampu mengurangi emisi GRK yang dihasilkan pada aktivitas penimbunan sampah secara langsung di TPA yang dapat terlepas ke atmosfer dalam jumlah besar, apabila kegiatan bank sampah atau pengelolaan sampah lainnya benar-benar dioptimalkan.
\end{abstract}

Kata kunci : Gas rumah kaca, Bank Sampah, Warm

\section{ABSTRACT}

Some of the problems that can arise from increasing population growth and economic growth are the increasing amount of waste in Banjar District, most of the waste can contribute to GHG in the form of methane gas (CH4). Waste that is accidentally piled up within a certain period of time can experience or decompose and can produce gases that will eventually spread in the air. Therefore, proper and environmentally friendly waste management needs to be done so that it does not pollute and damage the environment. Using the WARM (Waste Reduction Model) method is an application that functions to calculate GHG emissions from the waste sector by entering data that has been obtained into the application. The results of the analysis of the research that has been carried out is the existence of a garbage bank capable of reducing GHG emissions generated in landfill activities 
directly in the landfill that can be released into the atmosphere in large numbers, if the activities of the waste bank or other waste management are really optimized.

Keywords: GHG, waste banks, Warm

\section{PENDAHULUAN}

Bank sampah adalah salah satu alternatif mengajak warga peduli dengan sampah, menggunakan konsep yang mungkin dapat dikembangkan di daerah-daerah lainnya. Sistem pengelolaan bank sampah berbasis rumah tangga, dengan memberikan timbal balik berupa uang kepada mereka yang berhasil memilah dan menyetorkan sejumlah sampah. Dalam pelaksanaannya bank sampah dapat mengurangi tingginya angka sampah yang ada di masyarakat dan di TPA, karena masyarakat memilah sampah, menukarkan sampah ke bank sampah dan membuang sampah yang tidak termasuk di bank sampah. Dengan begitu volume sampah yang dapat dikurangi di masyarakat dan di TPA (tempat pemrosesan akhir) disebut dengan reduce (pengurangan volume atau jumlahnya). Pada dasarnya bank sampah merupakan konsep pengumpulan sampah kering dan dipilah serta mempunyai manajemen layaknya perbankan, tetapi yang ditabung bukan uang melainkan sampah. Warga yang menabung (menyerahkan sampah) juga disebut nasabah dan memiliki buku tabungan. Sampah yang ditabung akan ditimbang kemudian akan dijual di pabrik yang sudah bekerja sama dengan bank sampah. Sementara plastik kemasan dapat dibeli oleh pengepul yang sudah dikontrak oleh bank sampah, untuk didaur ulang dilakukan di bank sampah oleh petugas.(Anonim, 2012).

\section{METODE PENELITIAN}

\section{Lokasi dan Tempat Penelitian}

Penelitian ini dilakukan pada bulan Juni 2019 di Jalan Pendidikan, (Gg. Berkat Tawakal) Kecamatan Martapura Kabupaten Banjar, Kalimantan Selatan.

\section{Instrumen Penelitian}

Alat yang dapat digunakan dalam penelitian ini ialah sarung tangan, masker, alat tulis, gunting, tali rapia, timbangan digital, dan keranjang 500L. Sedangkan data yang digunakan terdiri dari data primer ialah data yang diperoleh dari observasi lapangan dan pengukuran langsung dilapangan. Data sekunder diperoleh dari instasi terkait seperti data berupa sebaran bank sampah serta jenis lahan urug TPA.

\section{Metode Analisa}

Menyelesaikan Penelitian ini diperlukan langkah langkah yang sistematis agar penyelesaiannya dapat berjalan dengan baik. Tahap pertama yang dilakukan yaitu tahap pendahuluan. Pada tahap pendahuluan perlu mempelajari jurnal penelitian, buku serta literature lainnya. Tahap kedua pengumpulan dan pengambilan data, untuk data sekunder seperti jenis lahan urug TPA dan data sebaran bank sampah Kabupaten Banjar. Sedangkan data primer seperti jumlah sampah yang masuk di Bank Sampah Sekumpul dan komposisi sampah.

\section{METODE PENELITIAN}

Sumber sampah yang dihasilkan, yang pertama pengambilan sampah dilakukan langsung oleh petugas, yang kedua pada saat masyarakat menabung sampah di bank sampah. Komposisi sampah pada Bank Sampah Sekumpul dapat diketahui berdasarkan penelitian yang dilakukan langsung di 
lapangan dengan menggunakan sampel keranjang sampah 500 L sesuai dengan SNI 19-3964-1994 yang dilakukan selama 8 kali.

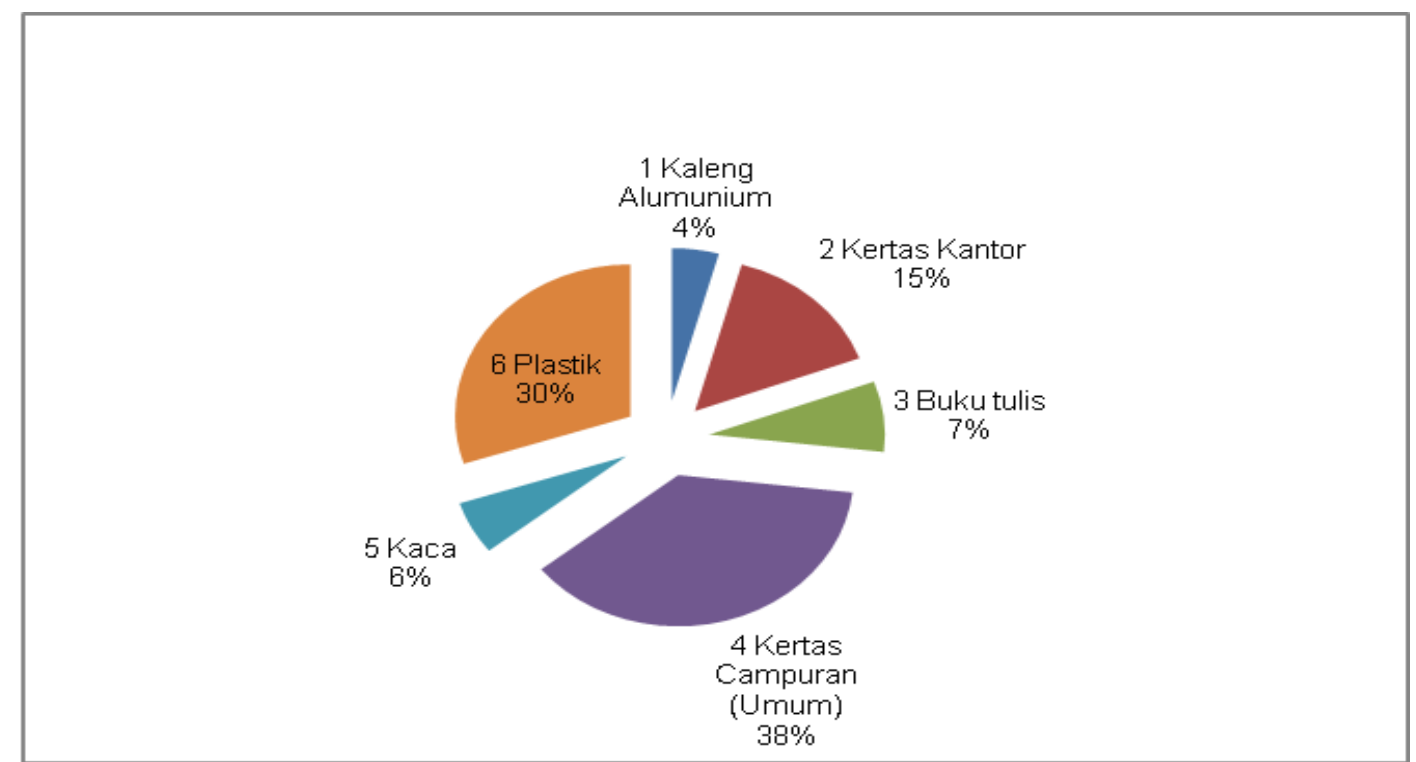

Gambar 3.1. Komposisi Sampah di Bank Sampah Sekumpul

\subsection{Persentase Reduksi Sampah pada kegiatan Bank Sampah Sekumpul}

Bank sampah berfungsi untuk mengurangi sampah yang masuk ke TPA dengan melakukan pengolahan terhadap sampah yang masuk, pegolahan yang dilakukan yaitu daur ulang (pemilahan sampah). Komposisi sampah pada bank sampah diperoleh dengan cara menimbang sampah yang dipilah oleh petugas bank sampah. Total sampah yang diolah oleh Bank Sampah Sekumpul yaitu sebesar 33.06 ton/tahun.

Tabel 3.1 Berat Sampah yang diolah oleh Bank Sampah dan dibuang ke TPA

\begin{tabular}{lcc}
\hline $\begin{array}{c}\text { Komposisi } \\
\text { Sampah }\end{array}$ & $\begin{array}{c}\text { BankSampah } \\
\text { (ton/tahun) } \\
\text { Sekumpul }\end{array}$ & $\begin{array}{c}\text { Jenis } \\
\text { Pengelolaan }\end{array}$ \\
\hline Kaleng & & \\
Alumunium & & \\
Kertas & & \\
Kantor & & \\
Buku Teks & 33.06 & \\
Kertas & & \\
Campuran & & \\
Kaca & & \\
Plastik & & Dibuang ke \\
\multicolumn{1}{c}{ Total } & $\mathbf{3 3 . 0 6}$ & TPA \\
Tekstil & & \\
& & \\
\hline
\end{tabular}




\begin{tabular}{lcc}
\hline $\begin{array}{c}\text { Komposisi } \\
\text { Sampah }\end{array}$ & $\begin{array}{c}\text { BankSampah } \\
\text { (ton/tahun) } \\
\text { Sekumpul }\end{array}$ & $\begin{array}{c}\text { Jenis } \\
\text { Pengelolaan }\end{array}$ \\
\hline Sisa & 172.14 & \\
Makanan & & \\
Sampah & & \\
lainnya & & \\
\hline
\end{tabular}

\subsection{Persentase Reduksi Sampah yang dihasilkan oleh Bank Sampah}

Perhitungan persentase reduksi sampah pada Bank Sampah menggunakan data jumlah sampah masuk pada Bank Sampah tersebut. Untuk mengetahui reduksi sampah yang dihasilkan, data jumlah sampah masuk dibandingkan dengan data sampah yang diolah oleh Bank Sampah Tujuan dari perbandingan data tersebut adalah untuk mendapatkan hasil reduksi sampah dengan adanya kegiatan pengolahan pada Bank Sampah dalam kurun waktu satu tahun.

Tabel 3.3 Presentasi reduksi sampah pada Bank Sampah

\begin{tabular}{cccccc}
\hline No Nama & $\begin{array}{c}\text { Jumlah } \\
\text { Sampah } \\
\text { Msuk } \\
\text { (ton/tahun) }\end{array}$ & $\begin{array}{c}\text { Daur ulang } \\
\text { Bank } \\
\text { Sampah } \\
\text { (ton/tahun) }\end{array}$ & $\begin{array}{c}\text { Residu } \\
\text { (ton/tahun) }\end{array}$ & $\begin{array}{c}\text { Persentase } \\
\text { Terkelola } \\
(\%)\end{array}$ & $\begin{array}{c}\text { Persentase } \\
\text { tidak } \\
\text { Terkelola } \\
(\%)\end{array}$ \\
\hline $1 \quad \begin{array}{c}\text { Bank } \\
\text { Sampah } \\
\text { Sekumpul }\end{array}$ & 205.20 & 33.06 & 172.14 & 16.11 & 83.89 \\
\hline
\end{tabular}

\subsection{Pengolahan Daur Ulang di Bank Sampah Sekumpul Menggunakan Metode WARM}

Perhitungan emisi GRK dari kegiatan daur ulang di Bank Sampah dapat di hitung menggunakan metode Waste Reduction Model (WARM). Perhitungan dengan metode WARM excel tool- base version 14. Data yang diperlukan dalam perhitungan ini berupa data berat sampah penduduk Kabupaten Banjar, data sampah yang di daur ulang oleh Bank Sampah, serta data sampah yang dibuang langsung ke TPA. Data-data yang diperlukan dalam perhitungan dalam waktu satu tahun dengan menggunakan satuan ton. Kegiatan daur ulang dapat menghasilkan GRK, hal itu disebabkan karena pada proses kegiatan daur ulang yang memerlukan energi, proses yang dilakukan ialah seperti pengumpulan, pemilahan, pengolahan awal, dan pemprosesan (Mahyudin,2014)

Berdasarkan tabel 4.8 jumlah sampah yang masuk di Bank Sampah Sekumpul yaitu sebesar 205.20 ton/tahun dengan emisi yang dihasilkan tanpa adanya bank sampah sebesar $67.47 \mathrm{TCO}_{2} \mathrm{E}$. Sedangkan untuk kegiatan daur ulang sampah yang saat ini dilakukan oleh Bank Sampah Sekumpul menghasilkan emisi sebesar $59.15 \mathrm{TCO}_{2} \mathrm{E}$, sehingga dengan adanya Bank Sampah Sekumpul emisi yang dapat dikurangi sebesar $8.32 \mathrm{TCO}_{2} \mathrm{E}$. Besar kecilnya angka dari emisi yang dapat dihasilkan oleh kegiatan bank sampah, jika sampah anorganik yang dihasilkan oleh bank sampah jumlahnya besar maka emisi yang dihasilkan juga besar. Maka dari itu perlu pengolahan sampah di bank sampah Kabupaten Banjar, tidak hanya di bank sampah yang aktif tetapi seluruh bank sampah yang ada di Kabupaten Banjar, karena semakin banyak bank sampah melakukan 
pengolahan sampah sebelum dibuang ke TPA maka akan semakin besar emisi yang dapat berkurang (Sibarani, 2019).

Tabel 3.4 Perhitungan emisi GRK dari kegiatan daur ulang TPS 3R di Kabupaten Banjar

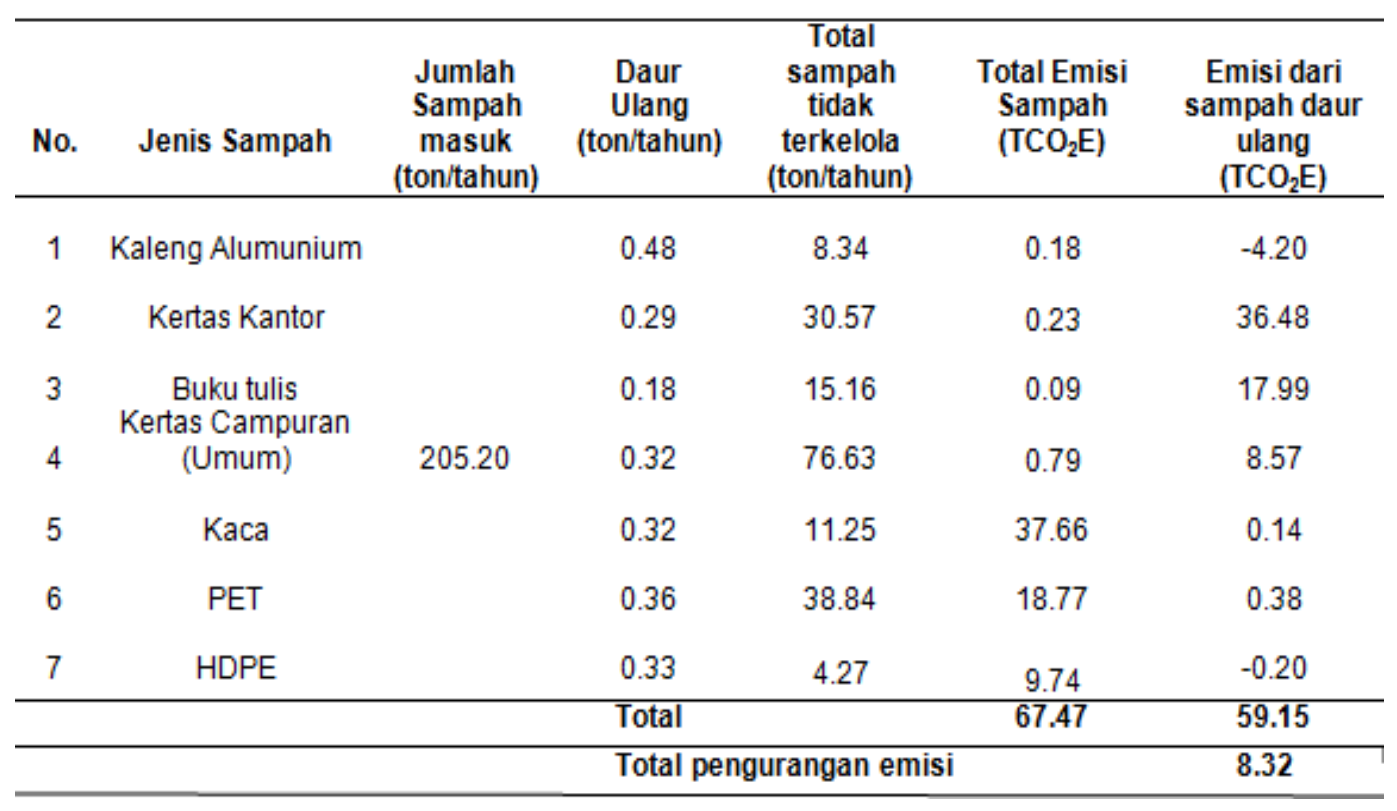

\section{KESIMPULAN}

Kondisi eksisting yang berkaitan dengan estimasi emisi gas rumah kaca di Kabupaten Banjar adalah pengelolaan sampah yang dilakukan oleh Bank Sampah Sekumpul adalah daur ulang sampah dengan total sampah masuk sebesar 205.20 ton/tahun. Berat Sampah yang diolah oleh Bank Sampah Sekumpul sebesar 33.06 ton/tahun, serta 172.14 ton/tahun yang dibuang ke TPA. Estimasi emisi gas rumah kaca yang dapat dihasilkan dari perhitungan skenario baseline (tanpa adanya bank sampah) sebesar $67.47 \mathrm{TCO}_{2}$ E. Sedangkan untuk skenario 1 menghasilkan emisi sebesar 59.15 $\mathrm{TCO}_{2} \mathrm{E}$ untuk Bank Sampah Sekumpul, sehingga dengan adanya Bank Sampah Sekumpul emisi yang dapat dikurangi sebesar $8.32 \mathrm{TCO}_{2} \mathrm{E}$.

\section{DAFTAR RUJUKAN}

Anonim. 2012. Profil Bank Sampah Indonesia. Jakarta

Juliandono. A. 2013. Pelaksanaan Bank Sampah Dalam Sistem Pengelolaan Sampah Di Kelurahan Gunung Bahagia Balikpapan Samarinda. Fakultas Hukum Universitas Mulawarman.

Mahyudin. R. P. 2014. Daur Ulang Dan Konservasi Energi Dalam Alternatif Pengelolaan Sampah Dengan Metode LCA. 203-207.

Manggar. L. C., Boedisantoso. R. 2016. Inventarisasi Emisi Gas Rumah Kaca Pada Sektor Pertanian Dan Peternakan Di Kota Surabaya. 36-41.

.Rusbianto. 2008. Global Warming for Beginner: Pengantar Komprenshif Tentang Pemanasan Global.

Sibarani. T. N. 2019. Estimasi Emisi Gas Rumah Kaca Dari Pengolahan Sampah Pada TPS 3R Menggunakan Pendekatan Integovermental Panel On Climate Change (IPCC) Di Kabupaten Banjar (Studi Kasus: TPS 3R Gudang Hirang Rt. 03, TPS 3R Taruna, TPS $3 R$ Kompas, TPS 3R Sekumpul).

Sudharto. H. 2004. Dimensi Lingkungan Perencanaan Pembangunan. 
JTAM Teknik Lingkungan Universitas Lambung Mangkurat, Vol 3 (2) Tahun 2020

Halaman ini sengaja dikosongkan 